\title{
ANÁLISE SOCIOSSEMIÓTICA CRÍTICA DE NARRATIVAS MIDIÁTICAS DOS 50 ANOS DA CAPITAL DO BRASIL
}

Simone Abrahão Scafuto (CEPADIC/UnB $)^{1}$

0 presente estudo analisa, com base em teorias sociais da linguagem e em perspectivas sociais e comunicativas, os significados produzidos por narrativas econômicas políticas veiculadas por revista brasileira de alto consumo e alcance global bem como os efeitos que projetam sobre a cognição social. Para isso, utiliza categorias de análise sistematizas pela Análise de Discurso Crítica e pela Semiótica Social da Multimodalidade, mediante as quais descreve e analisa significados discursivos e semióticos instanciados pelo uso simultâneo de recursos dos modos. Revela como os sentidos ideológicos do gênero são construídos e recontextualizados com o propósito de satisfazer interesses políticos e econômicos particulares e os efeitos de curto e de longo prazos que produzem sobre a vida em sociedade.

Palavras-chave: contexto; representação narrativa; mídia; análise.

The present study analyzes, based on social theories of language and on social and communicative approaches, the meanings produced by political economic narratives conveyed by Brazilian magazine of high consumption and global reach as well as the effects they project on social cognition. For this, it uses categories of analysis systematized by Critical Discourse Analysis and by Social Semiotics of Multimodality, through which it describes and analyzes discursive and semiotic meanings instantiated by the simultaneous use of modes' resources. It reveals how the ideological senses of gender are constructed and recontextualized for the purpose of satisfying particular political and economic interests and the short-term and long-term effects they produce on life in society.

Keywords: context; narrative; representation media; analysis.

\footnotetext{
1 Doutora em Linguística pela Universidade de Brasília (UnB). Consultora linguística da Universidade de Brasília (UnB). Membro do Centro de Pesquisa em Análise de Discurso Crítica - CEPADIC e da Associação Latino-Americana de Estudos do Discurso - ALED.
} 


\section{Introdução}

Os modos da linguagem verbal - oralidade e escrita - desempenharam e continuarão desempenhando importante papel nos mais variados contextos da vida em sociedade. Em contextos de interação face a face, a oralidade, por exemplo, é a principal modalidade de apreensão e de representação da realidade, devido às suas características intrínsecas, entre as quais, a facilidade de entendimento e de correção. Já a escrita, modalidade que perpassa as transformações da fala e à qual se atribui crescente valor social tem sido a escolhida para organizar e fixar a experiência humana em contextos sociais mais estruturados.

Os modos da linguagem não verbal - gestos, imagens, fotos, sons, movimentos, dança etc.- sempre representaram o mundo e os seus objetos em diferentes dimensões espaciais, mas têm sido cada vez mais usados em virtude da capacidade que possuem de representar com eloquência e rapidez as experiências humanas.

Isso significa que o desenvolvimento da informação e da comunicação social nas redes tecnológicas transformaram, de forma sem precedente, a produção dos textos e dos artefatos midiáticos. Em épocas anteriores, os textos traduziam os eventos do mundo em páginas preto e branco com recursos linguísticos exclusivos e com ilustrações graficamente uniformes. Em nossa época, era caracterizada pela dinamicidade e rapidez da comunicação, textos multimodais são os que preenchem com predominância os suportes - páginas, vídeos e telas - comunicativos.

Dado o propósito dos meios de comunicação midiáticos de informar à sociedade e a concepção de que o público requer atualização constante sobre os fatos e os acontecimentos, as narrativas midiáticas, gênero de texto ao qual a sociedade atribui credibilidade e valor, tornaram-se composições tão elaboradas e envolventes, que os espaços privilegiados dos principais suportes da mídia de massa são cada vez mais ocupados por elas.

Mas, apesar do importante papel sociocomunicativo desempenhado pela mídia, as representações midiáticas não são reproduções fiéis das estruturas da realidade como é do senso comum. As narrativas, sobretudo, as de alta visibilidade e consumo, têm sido reduzidas a ordens e informes para satisfazer os interesses das instituições dentro das quais elas saem.

Nascida da inquietação suscitada por leituras e reflexões acerca do poder simbólico exercido pela mídia como algo absoluto e definitivo, bem como da percepção 
do tempo difuso e desordenado das novas narrativas, o presente estudo qualitativo encontra na orientação transdisciplinar a metodologia apropriada para alcançar seus objetivos.

Com efeito, a presente investigação baseia-se na Análise de Discurso Crítica (FAIRCLOUGH, 2003, 2006, 2010), (KRESS; VAN LEEUWEN, 2006) (VAN DIJK, 2011) e nas ciências sociais (BAUMAN, 1999), (CASTELLS, 2009) e (THOMPSON, 2011) (MACQUAIL, 2013) com as quais mantém relação dialética, utilizando categorias metodológicas de análise da Análise de Discurso Crítica e na Multimodalidade (FAIRCLOUGH 2003) e na Multimodalidade (2006).

Inicialmente são abordados os contextos que regulam e controlam a produção e a difusão das narrativas midiáticas multimodais contemporâneas. A seguir, o estudo é fundamentado à luz das perspectivas teóricas que dão consistência e confiabilidade ao estudo. Em sua terceira parte, as categorias semióticas selecionadas e aplicadas aos dados de análise, são explicitadas. Considerações finais encerram o estudo realizado.

\section{Contextos globais e narrativas da mídia contemporânea}

A sociedade contemporânea se caracteriza pela preeminência de um sistema econômico inerentemente explorador, instituído por relações de poder derivadas da quantidade de recursos que detêm, as quais influenciam a estruturação e a reestruturação da sociedade de nossa época: o capitalismo. Regras, convenções e esquemas que governam o uso de recursos para produção dos bens de consumo estabelecem as diferenças materiais sobre as subjetividades e sobre as posições sociais, de maneira que a classe mais beneficiada desse sistema possa usufruir da relação estabelecida com os meios de produção. Neste contexto, o público consumidor é atraído e recrutado ao seu valor de investimento, seja ele genuíno, seja suposto, pois o objetivo da sociedade capitalista não é a satisfação de necessidades e de desejos dos cidadãos, mas a comodificação e a remodelação destes à semelhança do mercado consumidor (BAUMAN, 1999).

No processo de luta pelo poder econômico e político, a mídia, tipo de atividade social, política e econômica que envolve a produção/difusão e a recepção das formas 
simbólicas $^{2}$ e que reproduz as relações estruturantes do capitalismo, promove ativamente a fragmentação social, maximizando a sua potencialidade. Com efeito, as formas simbólicas, sobretudo as narrativas que retratam os eventos da realidade, tornam-se estruturas comunicativas com alto grau de criatividade, de seletividade e de julgamento. Em consequência, uma mudança termina por ocorrer no gênero porque as regras e os esquemas que o materializam são flexíveis (THOMPSON, 2011, p. 196-199).

\section{Comunicação globalizada e Estado-Nação}

Embora a globalização tenha sido compreendida como um fenômeno que incorpora uma transformação na organização espacial das relações sociais, que gera fluxos intercontinentais, redes de atividade e exercício de poder e, ainda, que se desenvolve rapidamente nas redes de interconexão e dependência, é tratada aqui como um contexto global que processa a informação e a comunicação nas redes tecnológicas com um caráter altamente genealógico, discursivo e estilístico.

De acordo com Fairclough (2006), a globalização tem sido confundida com o globalismo ${ }^{3}$, discurso que representa a globalização em termos neoliberais econômicos reduzidos, por meio de uma estratégia que flexiona e redireciona os processos reais da globalização. Viabilizado pela indústria global de comunicação por meio de relações com os centros de poder político e da influência exercida sobre a mídia de massa, o globalismo é uma modelo mental da sociedade de consumo que reinvindica valores, atitudes e identidades para promover as estratégias da indústria transnacional de comunicação.

Nas condições da globalização, a volatilidade das fronteiras e as constantes mudanças nas redes que estruturam as práticas sociopolíticas inevitavelmente provocam mudanças nos gêneros construídos nas intersecções das redes multidimensionais. Os gêneros globais transcendem redes e escalas de comunicação e são capazes de fornecer os limites necessários para redefinição de uma nova sociedade, todavia, sob a influência do discurso globalista, são reduzidos a formatos tecnológicos voltados a propósitos

\footnotetext{
${ }^{2}$ Formas simbólicas são formas e expressões significativas de textos e artefatos de vários tipos produzidos profissionalmente e recebidos por indivíduos situados em diferentes lugares no mundo sócio-histórico (THOMPSON, 2011).

${ }^{3}$ Globalismo é um discurso que representa a globalização em termos neoliberais econômicos reduzidos, por meio de uma estratégia que flexiona e redireciona os processos reais da globalização.
} 
promocionais. Textos globalistas multimodais, por exemplo, são aqueles que detêm maior potencial semântico para dar uma forma particular aos processos comunicativos. Isso significa que a comunicação governada por regras e preceitos globalistas reproduz formas de controle econômico e político sobre a realidade como se esta fosse um todo indistinto e indiferenciado.

Thompson (2012, p. 208) assinala que a produção de formas simbólicas favoráveis à liberalização do comércio transnacional da comunicação, a interligação das novas tecnologias e a distribuição e circulação dos produtos de informação no mercado global por agências internacionais são os fatores que mais contribuem para a homogeneidade das formas de representação da realidade.

Castells (2009, p. 39) também acentua que mesmo os Estados-Nação, sociedades estáveis de organização política, institucional e militar, parecem, sob a influência do poder da comunicação globalista, dissolver-se em espaços de interação e que, sendo assim, para se fortalecerem, transformaram-se em uma forma rede de Estado, por mecanismos que flexibilizam procedimentos de governança. Alguns se associaram em uma rede do Estado com múltiplos propósitos, outros constituíram-se como espaço de coordenação, de negociação e de debate com Estados interessados. Os mais fortes compartilham atributos de soberania estabelecendo rede permanente para elaboração de estratégias e administração da palavra. Estes modelos utilizam frequentemente a mídia como aparato para a governança.

\section{Mídia e a quase interação mediada}

Em seu estudo sobre a mídia, Silverstone (2011) afirma ser ela um amplo processo social econômico político que contribui para a capacidade humana de compreender o mundo, de produzir e de partilhar significados cotidianamente. Esse processo é assegurado por meio da mediação de mensagens cheias de conhecimentos, de crenças e de valores pautados por critérios e referências para a condução da vida diária compartilháveis. Todavia, como diz Fairclough (2006, p. 119-120) "a mídia, voz mais eloquente da globalização, também pode instituir o que não é real e o que é falso". Isso implica que os produtos informativos têm efeitos sobre a vida em sociedade.

De acordo com Thompson (2011), grande parte das narrativas midiáticas consumidas por um número indefinido de pessoas situadas em diferentes lugares do 
mundo é mediada por uma quase interação mediada4 ${ }^{4}$ Fairclough (2003, p. 30) esclarece que esse tipo de mediação é uma via de mão única produzida com poucas deixas simbólicas e sem a reciprocidade interpessoal da interação face a face e da interação mediada. Narrativas quase mediadas pela comunicação tecnológica envolvem, em muitos casos, textos e cadeias de gêneros ligados pelas novas convenções. Quando bemsucedidas, as narrativas de mão única podem ser, com relativa facilidade, recontextualizadas para servir interesses específicos. Assim, ainda que os consumidores das narrativas recontextualizadas sintam que não desfrutam incondicionalmente dos benefícios resultantes da "liberdade de expressão", cedem às novas relações sensoriais, fechando os sentidos e deixando-se moldar por elas.

Macquail (2013, p. 429) assegura, finalmente, que, em tempos de crise, a mídia é muito mais influente que nos momentos comuns. Nesse sentido, os eventos sociais representados pelos meios de comunicação de massa são intensos e planejados para garantir efeitos sobre a cognição social. Isso justifica o fato de as políticas e as regulamentações de hoje serem dirigidas a incentivar a mídia a fazer o bem e a impedir que ela cause danos sociais.

\section{Narrativas jornalísticas}

As narrativas são metáforas da realidade que tecem e permeiam as nossas vidas, possibilitando recriar histórias com base em valores internalizados em nossa memória cultural e demarcando o mundo social para ser apreendido em sua complexidade. Sabemos que em todos os tempos e lugares, as narrativas produziram significados constitutivos da realidade e que, por isso, os homens narraram, narram e continuarão narrando o mundo, seja por meio da imitação criativa das ações humanas, seja mediante a representação dos fatos situados no tempo e no espaço. As narrativas jornalísticas, por exemplo, são o capital precioso e fundamental à credibilidade do jornalismo. Para mantê-la, a política da mídia baseia-se no pressuposto de que a qualidade delas é absolutamente vital.

Motta (2013, p. 95-103) distingue as narrativas jornalísticas, classificando-as em reportagens de interesse humano (soft news), em narrativas de editoriais (hard news) e em narrativas históricas. As narrativas de interesse humano (dramas, tragédias, fatos

\footnotetext{
${ }^{4}$ A quase interação mediada é um tipo de interação que estreita a participação entre produtores dos textos e seus receptores, desobrigando-os a constituírem relações que, certamente, diminuiriam as incertezas quanto ao grau de entendimento e aceitação de suas mensagens (Thompson, 2011).
} 
insólitos etc.), por exemplo, permitem que o produtor narre os acontecimentos em estruturas semelhantes às das narrativas literárias, de modo a produzir efeitos estéticos. As narrativas de editoriais produzidas em terceira pessoa e em linguagem objetiva e direta não encadeiam sequências integrais, mas suas unidades temáticas podem ser deduzidas dos conhecimentos que elas atualizam estrategicamente. Finalmente, as narrativas históricas, cujas situações e eventos do presente são representados sequencialmente, difundem significados/sentidos que, embora provisórios, parecem eternos.

Destacamos que, para van Dijk (2011), embora os meios de comunicação produzam narrativas sobre eventos de mídia de abertura social, as que têm proeminência são as de conflitos reais ou assumidos. As melhores imagens e histórias geralmente servem às reportagens internacionais e na maioria das vezes elas aparecem com tamanho grande, chamada na primeira página e cobertura nas páginas interiores.

\section{Perspectivas Teóricas}

Abordamos aqui as teorias desenvolvidas no âmbito dos estudos do discurso que concebem o contexto como algo superveniente realizado nas formas de comunicação e de representação das experiências do mundo: a Teoria Sociocognitiva do Contexto (VAN DIJK, 2012), segundo a qual os contextos são modelos que controlam a produção do discurso e formam a base dos gêneros; a Análise de Discurso Crítica (FAIRCLOUGH, 2003, 2006, 2010), Teoria Social da Linguagem que investiga as relações de poder e de dominação produzidas pelos significados das formas simbólicas da mídia (THOMPSON, 2011); e a Teoria Semiótica Social da Multimodalidade (VAN LEEUWEN, 2005), (KRESS E VAN LEEUWEN, 2006), cujo pressuposto basilar é o de que os modos que integram os textos multimodais podem ser analisados em sua complexidade.

\section{Teoria Sociocognitiva do Contexto}

A teoria sociocognitiva do contexto é uma perspectiva integrada e multidisciplinar que define o contexto como modelo mental das propriedades relevantes das situações sociais e comunicativas que permanecem na memória episódica dos participantes das situações sócio-comunicativas e que, portanto, podem ser ativados conforme os interesses e as necessidades humanas. 
Em circunstâncias específicas, os modelos de contexto são estrategicamente ativados pelo uso dos recursos dos modos da linguagem para influenciar os modelos mentais dos seus receptores Entendemos que os níveis macro (global) e micro (local), os esquemas, os tamanhos e o eu mesmo são propriedades dos modelos de contextos, mas situações globais podem ser retratadas localmente e eventos locais como parte de contextos globais, especialmente, em situações de planejamento, quando o uso de capacidades gerais é requerido. De acordo com van Dijk (2012), a importância de um evento social reflete no tamanho das manchetes, fotos e imagens das narrativas veiculadas nos espaços privilegiados dos meios, e como os jornalistas autores das mensagens não são identificados, as histórias de fundo podem ser transportadas e editadas de maneiras diferentes.

Van Dijk (2012, p. 123-139) assegura que a compreensão e a interpretação do discurso realizadas pela mídia especializada requer conhecimentos contextuais que direcionam os processos de produção textuais por parte dos receptores das mensagens. Devido à impossibilidade de representar tudo o que os jornais e revistas já relataram anteriormente, estratégias cognitivas que ativam conhecimentos pessoais, novos, específicos, socioculturais e gerais são aplicadas nos processos discursivos e semióticos que compõem as narrativas, geralmente, organizadas por critérios de relevância e de interesse e não na ordem sequencial e cronológica original. A manchete de uma narrativa visual sobre evento local, por exemplo, destaca o que é mais interessante; no entanto, a informação relevante dependerá do modelo de contexto relacionado ao jornal, de que o editor quer publicar, do que os jornalistas sabem a respeito do assunto e do que o público está acostumado a ler.

\section{Análise de Discurso Crítica}

Originalmente baseada no construtivismo estruturalista de Bourdieu (1977), segundo o qual a vida social molda as estruturas sociais e é por estas moldada, e fundamentalmente orientada pela Linguística Sistêmica Funcional (HALLIDAY,1985), a Análise de Discurso Crítica (ADC), (FAIRCLOUGH, 1995, 2003, 2006, 2010) mantém dialógo irredutível com as ciências sociais preocupadas com as mudanças e as transformações aceleradas da sociedade contemporâneas para analisar as relações de 
poder e de dominação materializadas nos textos entendidos estes como o barômetro sensível das mudanças estruturais.

A Análise de Discurso Crítica da mídia evidencia a importância de considerarmos aspectos contextuais, como a natureza do mercado global dentro do qual os meios de comunicação tecnológicos (imprensa, rádio, televisão e internet) operam em redes de informação e a relação destes com os Estados-Nação. De acordo com Fairclough (2006 p.119-120), a análise das estruturas contextuais que influenciam o discurso da mídia contemporânea é importante porque apenas a análise dos aspectos institucionais que influenciam a produção e a recepção dos textos não é mais suficiente para explicar as mudanças recentes nas práticas sociais como parte das mudanças globais.

Além da questão dos efeitos do discurso da mídia tecnológica sobre a sociedade, há aspectos que corroboram para a produção de ideologias que servem a grupos hegemônicos: a representação dos acontecimentos por meio de códigos semióticos e por convenções e normas da mídia global, a recontextualização de formas sob a influência de interesses particulares e a naturalização dessas formas simbólicas pelo público acostumado a coberturas gerenciadas pela mídia transnacional e pela balança que exerce pressão nacional. Como o acesso às mobilizações geradas para a formação de uma opinião pública mais consciente é, infelizmente, restrito a uma esfera cosmopolita, as relações de poder e de dominação são mantidas e sustentadas com certa facilidade.

É importante destacar que o poder da comunicação é construído e exercitado por meio do gerenciamento de estruturas determinantes do poder sociopolítico e da comunicação de massa. Esse poder é precisamente operado por processos semióticos relacionados à prática sociopolítica relevante e realizado mediante a produção, a difusão e o consumo de narrativas compostas por metáforas e frames $^{5}$. Isso ocorre porque as narrativas, sobretudo as construídas por metáforas, são capazes de ativar a ansiedade, o medo, a insegurança etc., sentimentos e emoções que servem, portanto, como meio para influenciar, antecipar ou adiar processos de tomadas de decisão (CASTELLS, 2009, p. 142-145). Como não há um sistema rigoroso de análise com potencial de difusão, narrativas midiáticas são produzidas livremente e até com convenções literárias envolventes, posto que efeitos estéticos são elementos-chave para o seu consumo.

\footnotetext{
${ }^{5}$ Frames são estruturas narrativas que correspondem às estruturas neurais resultantes da atividade cerebral ao longo dos tempos.
} 
Em seus estudos sobre os meios de comunicação nas sociedades contemporâneas, Thompson (2011, p.76) assegura que a ideologia nas formas simbólicas está relacionada à ideologia das classes determinadas por relações objetivas de produção e por circunstâncias de caráter econômico e político. De acordo com o autor, para que as relações de poder e de dominação sejam mantidas, as formas simbólicas precisam ser (re)produzidas com significados específicos. Isso implica a existência de um sistema de meios e de fins operando em caráter global, conforme as condições e as circunstâncias de nosso tempo.

Sabemos que o discurso da mídia é o local de processos complexos e contraditórios e que, embora a ideologia não deva ser vista como uma constante e previsível presença em todo o discurso da mídia, muitos textos midiáticos funcionam como artefatos culturais para a reprodução da ordem e de ideologias dentro do mercado global competitivo. O valor simbólico atribuído pelos indivíduos que produzem e recebem formas simbólicas, por conseguinte, é, em grande parte, determinado pelo valor de compra e venda, portanto, um valor reconhecido por aqueles bem posicionados e que reconhecem e respeitam a posição daqueles.

Thompson (2011) chama a atenção para os modos típicos da ideologia operacionalizados nas formas simbólicas da mídia contemporânea, os quais fazem apelos à racionalidade das leis e a tradições memoriais, porquanto, muitas vezes, dissimulando as causas de conflitos reais e interligando os indivíduos em uma identidade coletiva, independente das diferenças e das divisões entre eles. Entre os principais modos de operação da ideologia estudados por Thompson (2001, p 81-89) estão a legitimação, a dissimulação, a unificação, a fragmentação e a reificação de ideias. Em vista do objetivo de nossa investigação, destacamos apenas a legitimação por narrativização. Assinalamos que a narrativização é uma das eficazes estratégias da ideologia incorporadas a gêneros da mídia porque é um modo de operação que trata o presente como parte de um passado eterno e dignificante, ainda que este passado tenha sido imaginado.

\section{Teoria Semiótica Social da Multimodalidade}

A Teoria Semiótica Social da Multimodalidade (TSSM) concebe a linguagem como um conjunto de modos de significação aos quais a representação e a comunicação recorrem para realizar diferentes trabalhos comunicativos (KRESS E VAN LEEUWEN, 2006). A teoria enfatiza que os significados das formas de comunicação empregados em uma cultura e implementados pelas novas tecnologias refletem o leque total das 
relações semânticas estabelecidas pelos diferentes modos semióticos (fala, escrita, imagem, som, movimento etc.) e que a integração realizada pelo uso apropriado dos recursos de cada modo semiótico em representações da experiência e dos objetos do mundo social produz e reproduz significados comunicativos que são determinados por motivações e pelos interesses do contexto social (JEWITT, 2011). Entendemos que a investigação apropriada das formas midiáticas multimodais envolve a comparação, a análise e a avaliação das representações, em termos de onde elas vêm, do que incluem e excluem, do que realizam no primeiro plano, no plano de fundo, em termos dos interesses que influenciam a sua formulação e projeção e para quem elas são dirigidas.

Ao tratar da narrativização, Kress e van Leeuwen (2006) esclarecem que, em imagens subjetivas, a narrativização é realizada por ângulos (elevados e frontais) indicativos de poder e de envolvimento, e que em imagens objetivas é configurada por ângulo perpendicular (de cima para baixo) indicativo de potência máxima. Tais ângulos sugerem posições de espectadores capazes de neutralizar as distorções comuns da perspectiva. Para estabelecer um ponto de vista, o imaginário do espectador é ativado por meio da inclusão de algo ou de alguém que, em maior ou menor grau, aparece no primeiro plano da imagem. Os diagramas, os mapas e os gráficos são formas que geralmente codificam uma atitude objetiva; mas o ponto de vista, geralmente representado pela transversalidade e pela visão de raios $X$, permite ao analista sondar, além da aparência e da superfície, os níveis mais profundos e ocultos das situações e dos eventos narrativizados.

\section{Metodologia}

A análise dos modos de construção dos significados das narrativas encontra, no triângulo discurso - cognição - sociedade, a orientação metodológica apropriada. Com efeito, o sentido de discurso aqui utilizado é o de acontecimento comunicativo em qualquer dimensão semiótica, cognição implica a cognição pessoal e coletiva - crenças, valores e emoções envolvidas nos processos de produção dos textos - e sociedade inclui as estruturas econômicas e políticas, definidas em termos de organização, instituição, relação de grupo, processo social etc.

Embora as bases teóricas adotadas aqui possuam cada uma seus instrumentos teóricos e analíticos, a relação dialética estabelecida entre as perspectivas busca dar confiabilidade a análise dos dados. É necessário destacar que a noção sociocognitiva de contexto contrasta com a visão sistêmica funcionalista da linguagem, mas não invalida a 
análise proposta, tendo em vista que a metodologia adotada tem foco multipragmático (DENZIN; LINCOLN, 2010). A decisão de aplicar o instrumento analítico também resulta de uma atitude política consciente.

Acrescentamos que a relação triádica entre discurso, cognição e sociedade para a análise de dados provém da percepção da existência de uma relação intrínseca entre o contexto e o discurso (semiose) e de que o texto, como parte do evento social desenvolvido da prática social, inevitavelmente, reflete as estruturas contextuais que controlam a sua produção. Isso implica dizer a produção e a compreensão do discurso em uso na sociedade dependem dos modelos de contexto (conhecimento) armazenados na memória.

A imagem a seguir ilustra a orientação metodológica adotada na análise de narrativas midiáticas contemporâneas:

Figura 1 - Orientação metodológica da análise de narrativas midiáticas

\section{Contextos}

Semioses

\section{Ideologias}

Fonte: a própria autora.

É útil contrastar texto e imagem e considerar que onde há formas diferentes de significação da experiência, há diferenças no significado. Todavia, como textos e imagens integram-se nas estruturas narrativas constituindo uma composição coerente, é difícil separá-los (BAUER E GASKELL, 2005).

Ressaltamos que, uma vez que a Multimodalidade descreve e interpreta os modos semióticos dos textos produzidos por normas e regras motivadas por interesses de um contexto específico (JEWITT, 2011), a análise das categorias - gênero global, representação narrativa e modalidade - envolve a análise do contexto de produção e os modos da ideologia incorporados às semioses. Para a compreensão das análises, são explicitadas as categorias. 


\section{Gênero Global}

Machine e van Leeuwen (2007) afirmam que os gêneros que promulgam e perpetuam as relações de poder em escala global são os que se tornam verdadeiramente globais. Assim, o que se torna óbvio no gênero global (os layouts) deve ser mantido porque distribui valor e estilo de vida. Os gêneros globais midiáticos são organizados por imagens e seguem a mesma ordem do discurso: a imagem referente ao problema é seguida da imagem da solução, podendo o problema pode ser representado verbalmente e a solução visualmente. 0 problema formulado por uma pergunta geralmente cria uma relação direta com o agente e a solução formulada por uma afirmação estabelece uma ordem persuasiva. Embora os gêneros globais sejam formas de comunicação cultural e historicamente específicas, tornam-se modelos estratégicos globais usados para o exercício do poder porque estruturam e estabelecem relações entre as partes que se comunicam.

\section{Representação Narrativa}

Representações narrativas visuais não são simples reproduções de estruturas da realidade como é do senso comum, mas artefatos planejados e elaborados para atender as instituições dentro das quais são produzidas, circuladas e lidas. As representações narrativas contêm participantes, processos de ações, eventos e combinações espaciais para retratar os eventos culturalmente congruentes. Diferentemente de uma representação conceitual a representação narrativa caracteriza-se pela presença de um vetor que pode ser formado por linhas retas ou diagonais, por linhas de conexão indicativas de que algo está relacionado, por órgãos, por ferramentas etc. De acordo com os semioticistas Kress e van Leeuwen (2006, p. 47-59), há dois tipos de participantes envolvidos nas representações narrativas: os participantes interativos aqueles que falam, ouvem, lêem, produzem e visualizam - e os participantes representados - personagens ou pessoas, lugares e coisas em determinadas circunstâncias. 
Figura 2 - Participante interativo

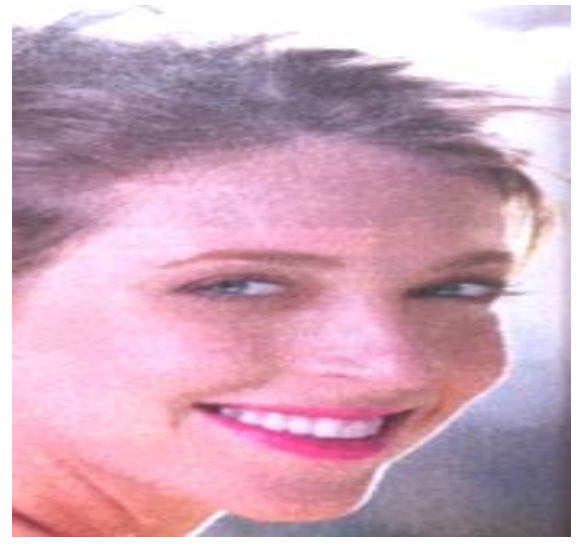

Figura 3 - Participante representado

\section{iPad mini}

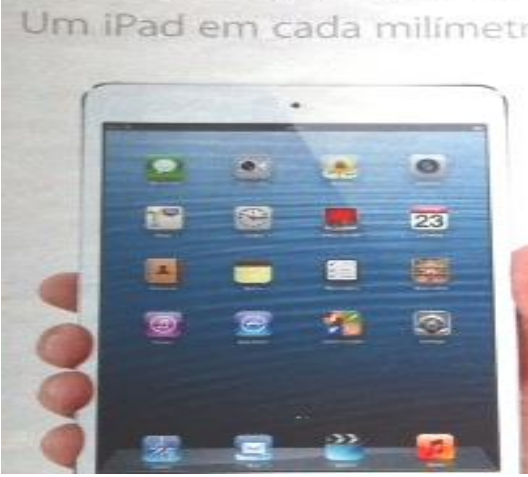

Fonte: Revista Veja, Editora Abril, Edição 2.328, ano 46, n. 27, p.10 e 25.

Em representações narrativas os participantes principais relacionam-se aos participantes (meta) por meio de processos de ação que podem ser identificados pelo tamanho, colocação, contraste com o fundo, grau de saturação da cor, nitidez de foco e saliência psicológica. Participantes dos quais o vetor emana, apontando para uma meta representam a relação como uma transação (Fig. 4). Nesse caso, o laptop é o participante meta. Os participantes que desempenham os papéis de portador/atributo representam outros participantes, o todo e as suas partes (Fig. 5). Nesse caso, o participante ator representado pela mão é o portador e o iPad o atributo.

Figura 4 - Participante meta representado

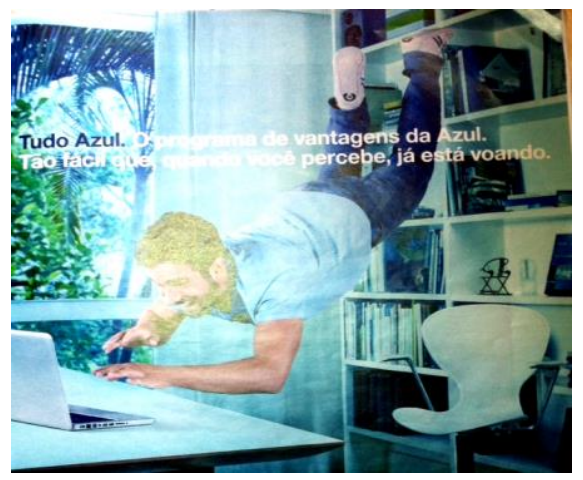

Figura 5 - Participante portador de atributos

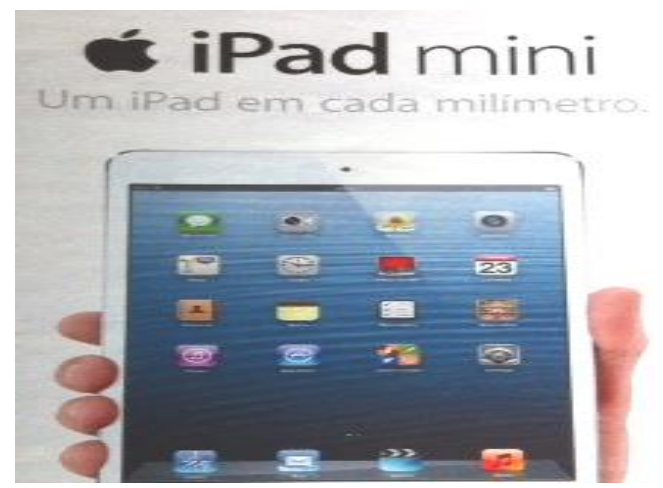

Fonte: Revista Veja, Abril, Edição 2.328, ano 46, n. 27, p.33 e 25.

As formas geométricas também podem representar participantes. Quadrados e retângulos (edifícios, estradas etc) são elementos da construção humana que indicam honestidade e ordem, mas dependendo do contexto, podem ser fonte de opressão. Elementos representados por círculos indicam auto-suficiência, proteção e eternidade. 0 
triângulo, elemento da ordem tecnológica, representa poder, hierarquia, direcionalidade, mas quando inclinado pode significar conflito ou tensão. 0 alongamento horizontal das formas provoca um tipo de estrutura que posiciona a informação antiga do lado esquerdo e a informação nova do lado direito. Embora compreendida racionalmente, a angularidade pode ser associada ao mundo inorgânico e ao tecnológico. Isso significa que quanto mais abstrato o sinal, maior seu potencial de utilização.

Destacamos que os processos de ação existentes nas estruturas narrativas diferenciam-se com base no vetor, nos participantes envolvidos e no contexto. Podem ser transacionais, não transacionais, mentais, verbais e de conversão. As representações com processos de ação transacional possuem dois participantes (ator e meta), mas o participante ator não instiga o movimento transacional ao participante meta, pois o ato colocado em primeiro plano deve levar os receptores aos bens e aos serviços demandados. Estas estruturas transacionais podem ser bidirecionais - o participante age como ator em um momento e como meta em outro. Já as estruturas não transacionais possuem apenas o participante (ator), porque a ação não é dirigida para alguém ou para algo. As que representam os participantes como metas são os eventos, pois os agentes das ações não são completamente visíveis e as ações não transacionais que adicionam participantes secundários representam-nos apenas como circunstâncias. Quando o vetor é formado pelo olhar do participante representado (reator) em direção a uma meta (fenômeno) o processo é reacional, podendo este ser formado por estrutura transacional ou não transacional. Os espectadores de uma estrutura com processo reacional podem ter empatia pelo participante que olha para o não visível, a exemplo dos close-ups cujos processos não transacionais usam os participantes (reatores) como fontes de manipulação. Reações transacionais como conteúdos da percepção e da emoção, por exemplo, são mediadas por balões de pensamento (reatores), como conteúdos do discurso, por exemplo, balões de diálogo (sensor). Em estruturas com processos de conversão há um terceiro tipo de participante (relay) que sempre transforma o que recebe, podendo pode ser ator em relação a um participante e meta em relação a outro participante. Na comunicação representada como um ciclo os participantes são relays e a agência é fracamente significada (KRESS E VAN LEEUWEN, 2006, p.59-69).

Finalmente, as circunstâncias, especialmente as locativas, elementos secundários relacionados a um participante específico, são representadas por meio do contraste entre primeiro e segundo plano, da sobreposição de gradientes e do grau de saturação da cor, podendo estas ferramentas constituirem vetores. As circunstâncias de acompanhamento em imagens não contêm vetores. Participantes secundários são 
circunstâncias que podem ser ignoradas porque não afetam a proposição básica (KRESS E VAN LEEUWEN, 2006).

É importante, por fim, distinguir a representação narrativa da conceitual. Um participante frontalmente colocado contra um fundo ausente ilustra mais uma representação conceitual do que uma representação narrativa. Os participantes são representados de forma generalizada, mais ou menos estável e atemporal. 0 exemplo a seguir mostra os participantes relacionados a mesma categoria abrangente.

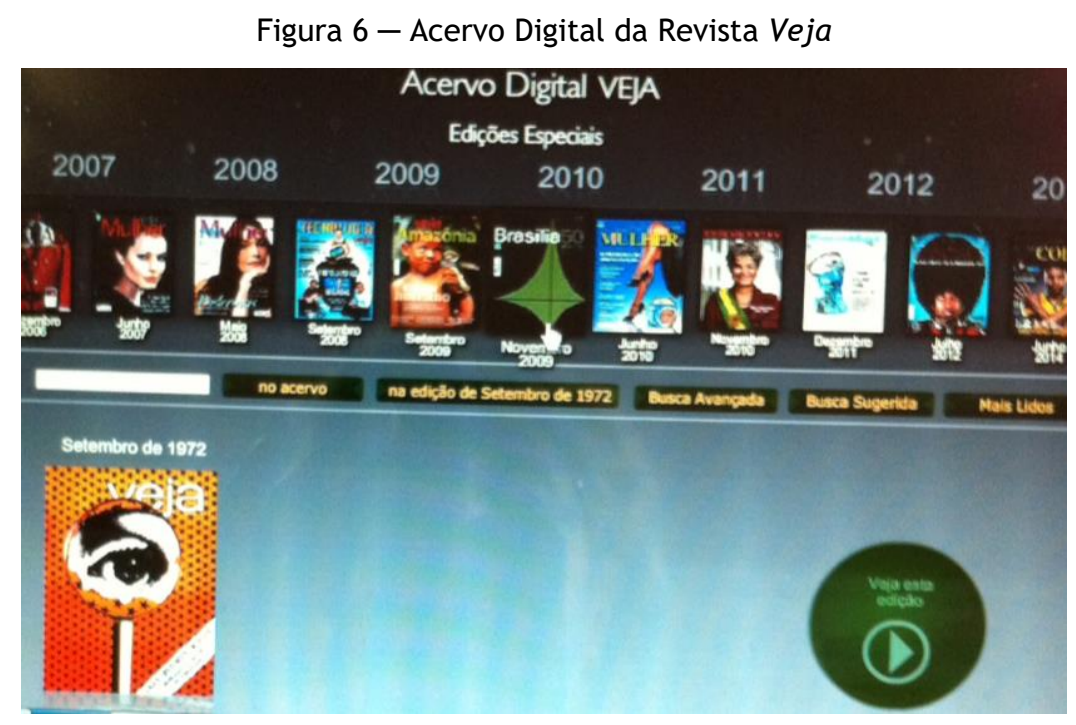

Fonte: http://veja.abril.com.br/acervodigital/

Nesse caso, há uma taxonomia na qual o participante superior é inferido a partir de similaridades entre os participantes subordinados dispostos simetricamente no texto. Para manter a natureza estável e atemporal da classificação, os participantes são mostrados de forma descontextualizada. O fundo é simples e neutro, a profundidade é redutora e ausente, o ângulo é frontal e objetivo e no espaço da imagem há palavras.

\section{Modalidade}

A modalidade é uma categoria de análise da comunicação visual que nos permite descrever e analisar, por meio de uma série de sinais e de modos gerais de expressão, o que é ou não real, o que é verdadeiro ou falso. Com base na aparência das coisas e na quantidade de correspondência entre o que é visto em um cenário concreto e específico e o que se vê em uma representação visual, podemos analisar a modalidade. A 
credibilidade nas mensagens jornalísticas, por exemplo, baseia-se no conhecimento das fotografias porque estas representam o visível com maior definição, profundidade e modelagem. Porém, devido à resolução da foto digital, as análises devem ser realizadas com mais cautela. Em termos dos critérios naturalistas, a cor é marcada em uma escala que vai da completa saturação para a ausência de cor; de uma gama de cores para o monocromático; de cores totalmente moduladas - tons diferentes de vermelho - a cores não moduladas (KREES E VAN LEEUWEN, 2006).

Outros marcadores chave da modalidade visual são a contextualização, a representação, a profundidade, a iluminação e o brilho. A contextualização pode ser marcada por uma escala que vai da ausência de fundo (modalidade reduzida) para um fundo mais plenamente articulado, detalhado e nítido (baixa modalidade). Em uma escala corrida, a representação vai da máxima abstração para a máxima representação de detalhes, mas na fotografia, a nitidez de foco e a exposição podem reduzir detalhes em maior ou menor grau. A representação de participantes reduzida de detalhes é mais modalizada no primeiro plano e menos no fundo - os participantes ligados a uma localização e a um momento temporal específico são representados genericamente. $\mathrm{Na}$ escala da profundidade, a perspectiva central tem maior modalidade, seguida por perspectiva isométrica angular e frontal e pela profundidade criada pela sobreposição. A iluminação, em uma escala corrida, vai da representação mais completa do jogo de luz e de sombra até a sua ausência no extremo da escala. 0 brilho, em uma escala contínua, parte de um número máximo de diferentes graus de luminosidade, podendo, seus valores contrastarem em maior ou menor grau em uma foto, a diferença entre a área mais escura e a mais clara pode ser grande, na outra, a diferença pode ser mínima, de modo que o efeito nebuloso é criado. Disso resulta que a modalidade é realizada por uma complexa interação de pistas; porém, uma avaliação global da modalidade é realizada pelo espectador.

Como vimos, a aplicação da categoria gênero global em nossos dados nos permite perscrutar como são estruturados e organizados. A análise da categoria representação narrativa nos possibilita explanar os modos dos participantes, os processos ativados nos textos e as circunstâncias que os constituem. Por fim, a análise da modalidade nos leva a identificar, por meio do uso de marcadores, o propósito, o ponto de vista dos textos e os valores neles implícitos. 


\section{Análise semiótica crítica}

Figura $6 a-50$ anos de Brasília

Revista Veja 11/2009, capa

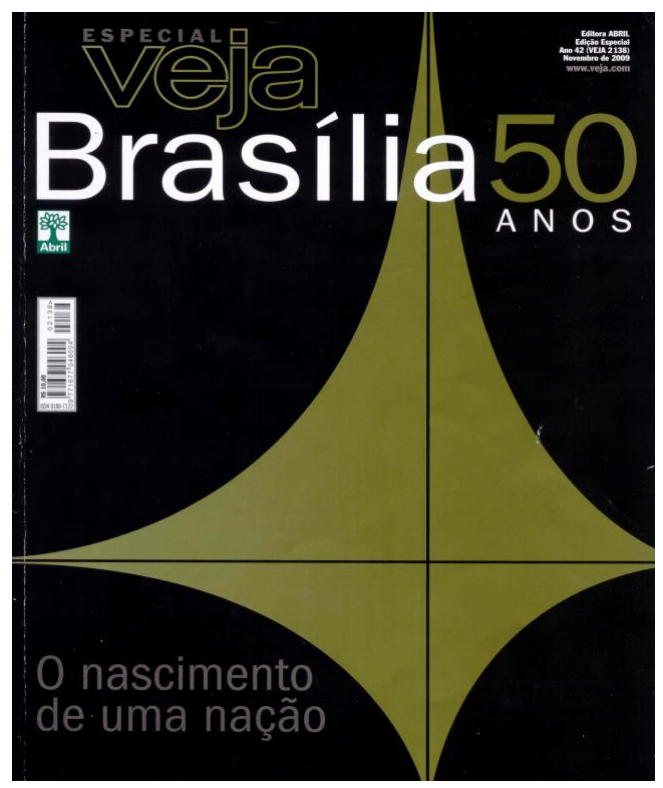

Fonte: Edição Especial, Abril, ano 42, n. 2.
Figura 6b - 50 anos de Brasília

Revista Veja 11/2009, p. 47

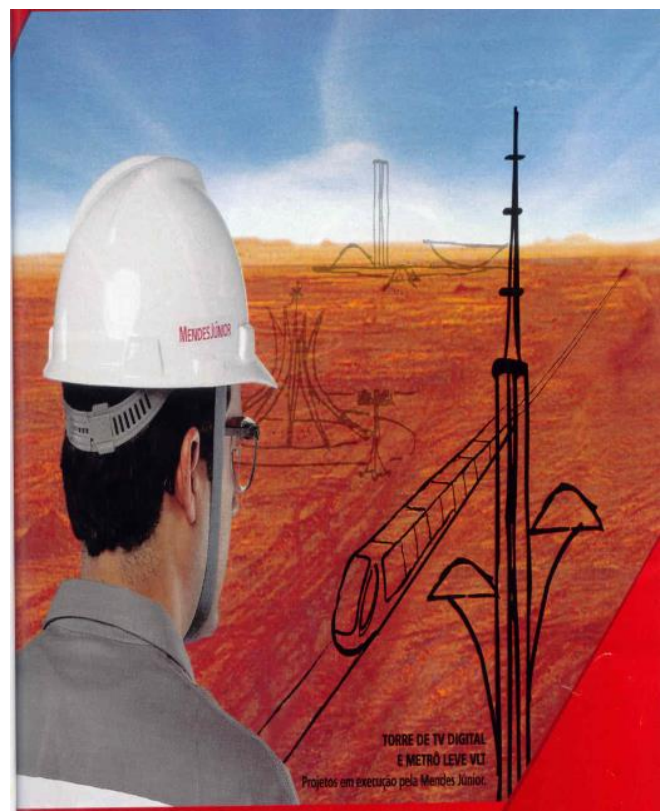

Fonte: Edição Especial, Abril, ano 42, n. 2.

\section{Contexto de produção}

Os textos multimodais acima são produtos informativos elaborados sob 0 controle de modelos de contextos globais e locais e amplamente difundidos por edição especial da Veja de outubro de 2009. Fruto do aperfeiçoamento de processos globais e da produção convergente dos meios impresso e on-line, essas formas simbólicas, do tipo quase interação mediada, possuem alto grau de criatividade, de seletividade e de julgamento, porque nelas estão implementadas condições como: capital, regras, convenções, esquemas, interesses políticos e objetivos econômicos.

A Veja, revista de distribuição semanal com tiragem superior a um milhão, trata de temas de abrangência nacional e global. Entre os temas tratados com frequência estão questões políticas, econômicas e culturais. A revista movimenta a economia para o consumo, valoriza a comunicação globalizada, estimula a privatização e a competitividade no espaço aberto a informações e a anúncios publicitários. Foi alvo de 
processos judiciais por partidos políticos e por políticos, sendo condenada em alguns casos e absolvida em outros.

Os textos em focalizados acima têm como contexto local um evento social de domínio público: o aniversário de 50 anos da Capital do Brasil. Os textos são narrativas organizadas em um formato que transcende redes particulares de comunicação e escalas. O gênero midiático combina os recursos da escrita e da imagem com a finalidade de produzir significados. Enquanto o texto referente à Fig.6a tem como objetivo comunicativo atualizar um conhecimento sócio-histórico amplamente compartilhado, o texto da Fig. 6b tem como propósito alcançar um resultado particular.

\section{Contexto sócio-histórico}

Figura 7a - Missão Cruls (1892-1893)

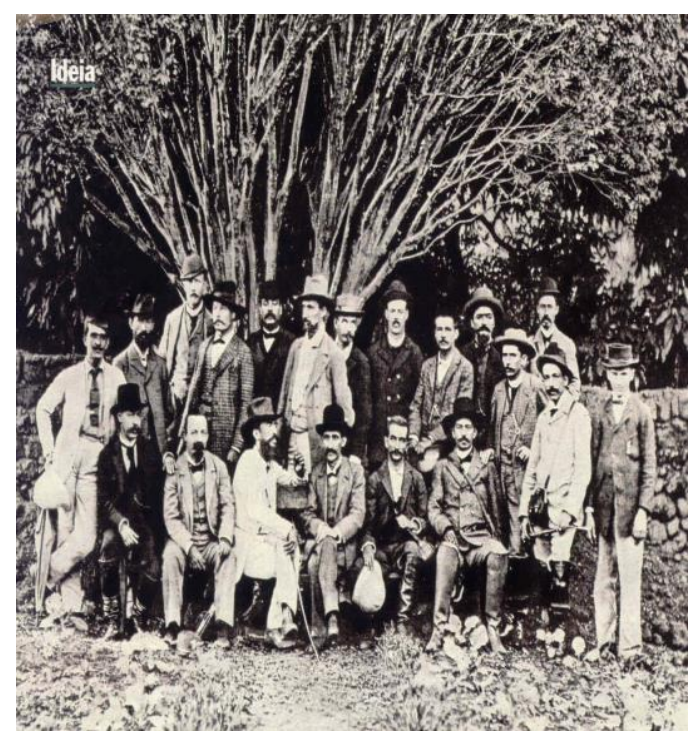

Fonte: Foto do arquivo público nacional
Figura 7b - Quadrilátero Cruls

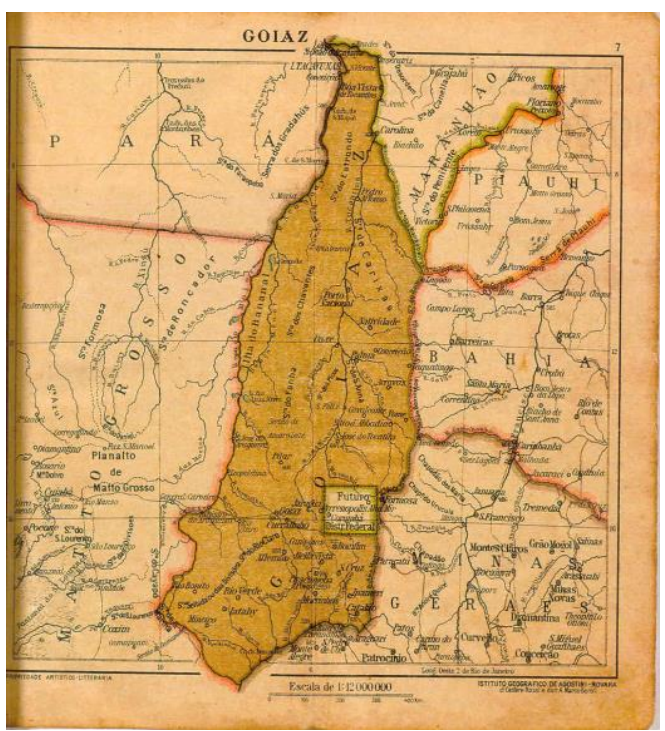

Fonte: Mapa do arquivo público nacional

Os registros da história da capital do Brasil revelam que a Missão Cruls, grupo liderado por um astrônomo belga que fez o primeiro levantamento da região no Planalto Central, onde seria construída a capital (antes chamada Vera Cruz), demarcou um quadrilátero na região de Goiás que indicava as distâncias entre as capitais estaduais do país. 
Figura 8a - Missão José Pessoa (1954)

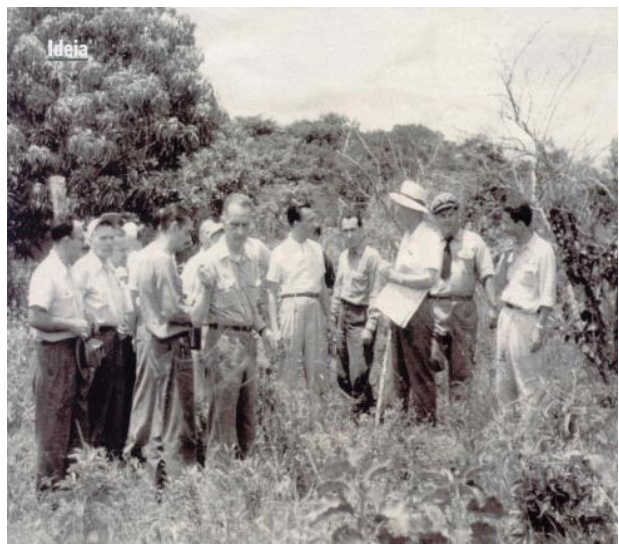

Fonte: Foto do arquivo público nacional
Figura 8b - Esboço de Vera Cruz

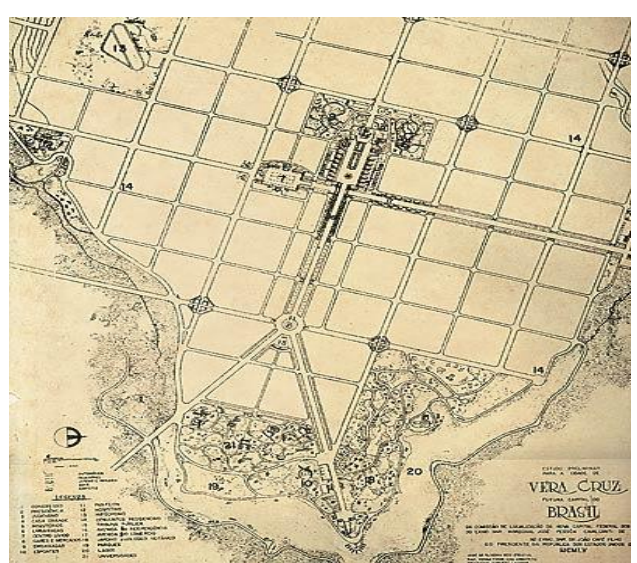

Fonte: http: //terradeencantosbrasil.

Nomeado pelo Presidente Café Filho, o Marechal José Pessoa liderou a Comissão de Localização da Nova Capital, na trilha aberta pela Missão Cruls, o qual mandou erguer uma cruz de madeira no ponto mais alto do cerrado. O planejamento incluía rede de esgoto, ferrovias, rodovias e os orçamentos para a construção da nova capital, mas o Marechal, posteriormente, renunciou à comissão para não emitir parecer, porque o projeto de planejamento não estava concluído.

Assim, um esboço de Brasília já existia antes mesmo de Lúcio Costa e de Niemeyer elaborarem o projeto urbanístico e os monumentos de Brasília, antes de a Capital do Brasil ser construída e de tornar-se Patrimônio da Humanidade.

Fig. 9 - Maquete de Brasília, 22/11/1958

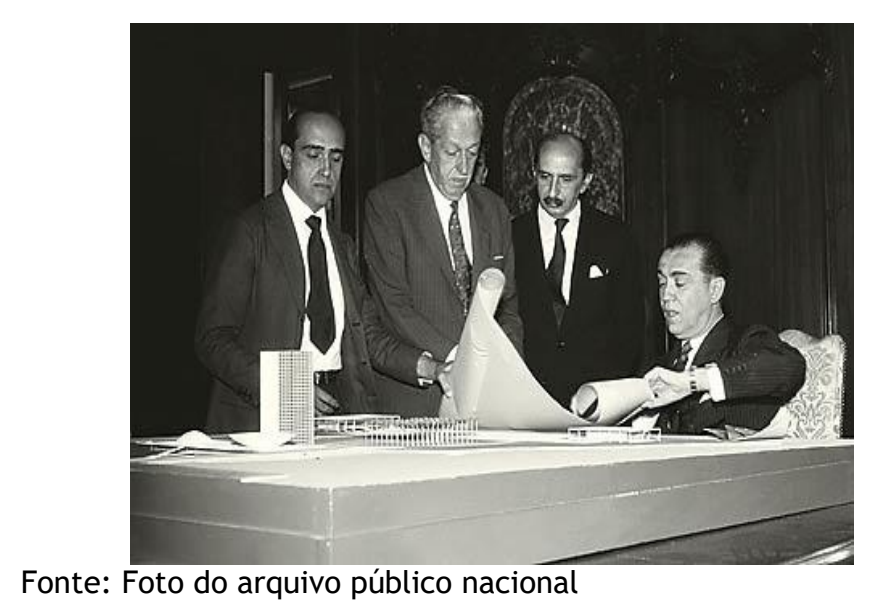

${ }^{6}$ Da esquerda para a direita: Oscar Niemeyer, Israel Pinheiro, Lúcio Costa e Juscelino Kubitschek. 
Figura 10 - Patrimônio da Humanidade (Plano urbanístico de Brasília-DF)

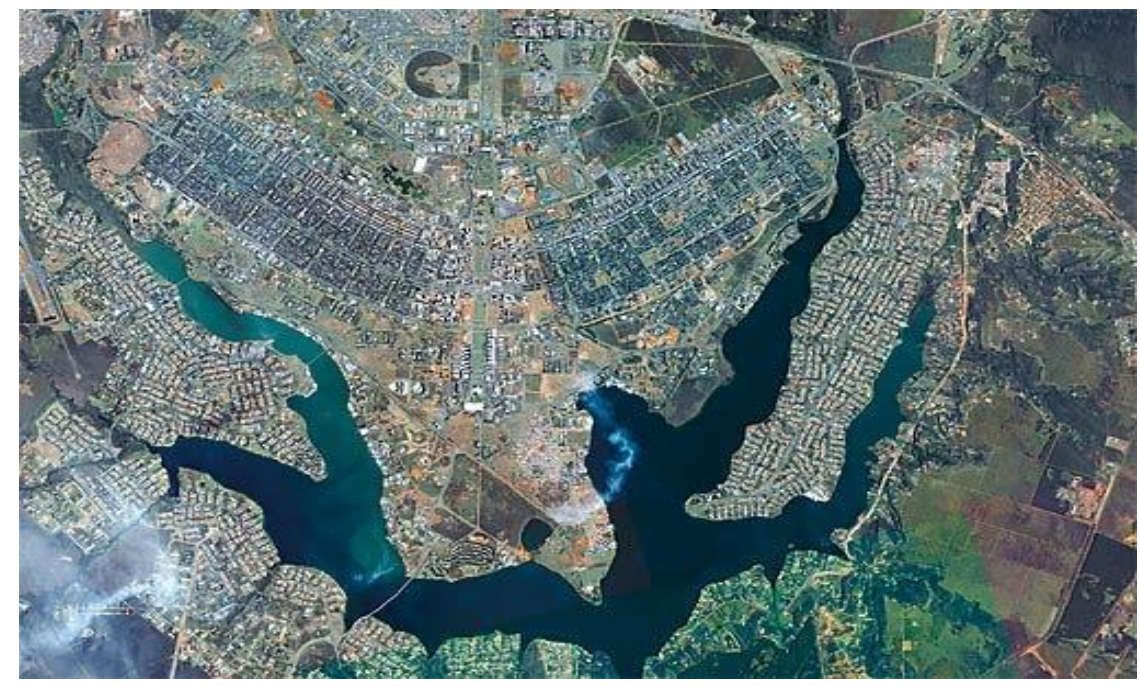

Fonte: http://veja.abril.com.br/especiais/brasilia/primeira-vez-mapa-p-020

Análise do Texto 1

Figura 6a - 50 anos de Brasília Revista Veja, 11/2009, Capa

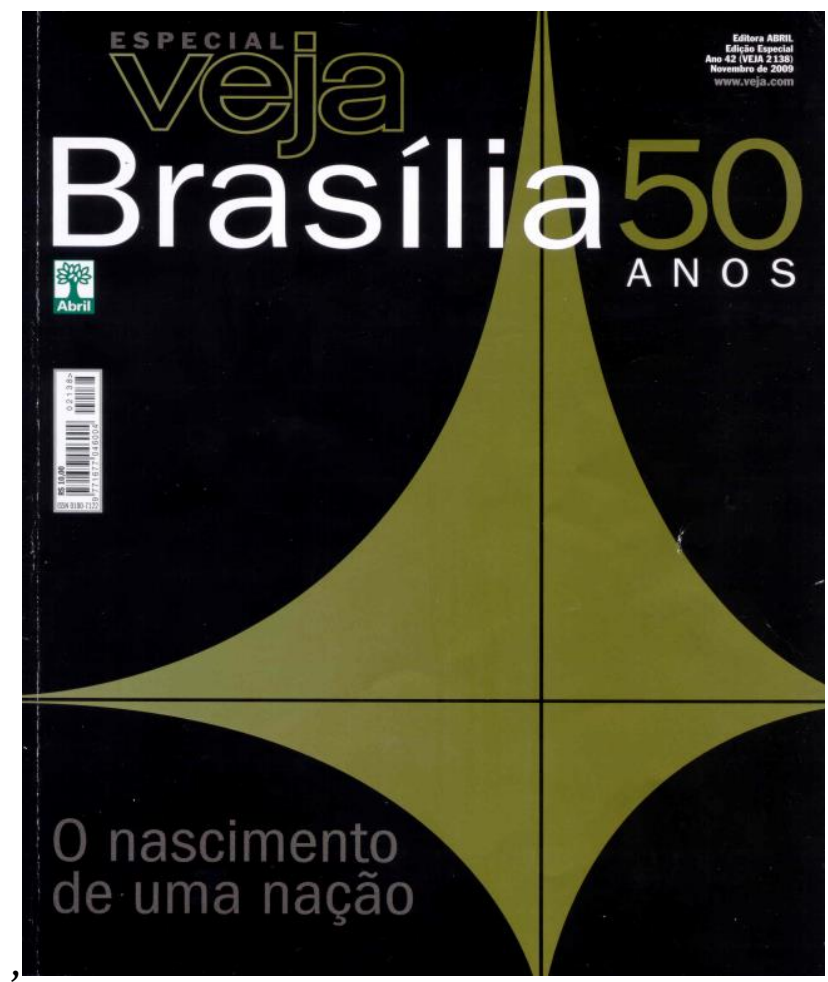

Fonte: Veja, Edição Especial, Abril, ano 42, n. 2.138

A representação midiática acima (Fig. 6a) é materializada discursivamente por meio da expressão Brasília 50 ANOS e da expressão 0 nascimento de uma nação. Ambas ativam conhecimentos que no decorrer dos anos foram construindo a identidade 
cultural. Concretiza-se visualmente por meio da composição de formas semelhantes às colunas do Palácio do Planalto 7 . A perspectiva de ângulo frontal na composição cria envolvimento máximo com os receptores da mensagem. Recursos semióticos como: a elevação da linha vertical que ultrapassa a expressão saliente Brasília 50 ANOS; o triângulo formado pelo vértice das colunas; e o alongamento da linha horizontal à esquerda sob a qual é disposta a expressão dada $O$ nascimento de uma nação, evocam o sentido de direcionalidade, poder e solidez do Estado-Nação.

A integração dos modos semióticos organiza um gênero global, cujo layout se apresenta com uma estética que poder ser facilmente guardada na memória de seus receptores. O significado político do texto é legitimado pela narrativização, um modo estratégico da ideologia que expressa o presente como sendo parte de uma tradição memorável e dignificante, operacionalizada por meio da inserção da cruz (símbolo do cruzamento do eixo monumental com o rodoviário). Embora pareça conceitual, a estrutura é narrativa, porque a cruz que divide o quadro em quatro frames de tamanhos distintos, cujas linhas emolduram dois lados de cada frame demarcado na composição de fundo escuro, é o próprio vetor do processo de ação não transacional. Na representação narrativa há somente um participante meta, ou seja, um evento (aniversário de 50 anos da Capital do Brasil) representado pela composição das colunas do Palácio do Planalto delimitadas por uma cruz cujos frames carregam valor informativo. Os quatro frames representam as quatro escalas hierárquicas do plano urbanístico de Lúcio Costa para Brasília: i) o eixo monumental (onde estão os palácios e os ministérios); ii) a escala gregária no cruzamento dos eixos (onde ficam a rodoviária e os centros comerciais); iii) a escala residencial (onde estão as superquadras); iv) a escala bucólica (onde estão as enormes áreas verdes e os parques de Brasília).

A expressão 0 nascimento de uma nação exposta na parte inferior do design, sob o vértice mais ou menos alongado das colunas dispostas à esquerda atualiza a história da Capital Federal, conhecida como Patrimônio Cultural da Humanidade. O evento cultural de domínio público é identificado pelo modo escrito: Brasília 50 ANOS. Porém, como a composição do modo visual inclui, na representação da Nação, apenas o poder executivo (os poderes legislativo e judiciário são excluídos), inferimos que o texto foi planejado

\footnotetext{
${ }^{7}$ Palácio do Planalto é o nome oficial do Palácio onde está localizado o Gabinete da Presidência da República Federativa do Brasil. 0 prédio também abriga a Casa Civil, a Secretaria-Geral e o Gabinete de Segurança Institucional da Presidência da República. É a sede do Poder Executivo do Governo brasileiro. 0 edifício está localizado na Praça dos Três Poderes em Brasília, tendo sido projetado por Oscar Niemeyer e inaugurado em 21 de abril de 1960.
} 
para projetar um efeito de sentido específico: fortalecer a autoridade do governo brasileiro.

Análise do Texto 2

Figura $6 \mathrm{~b}-50$ anos de Brasília

Revista Veja, 11/2009

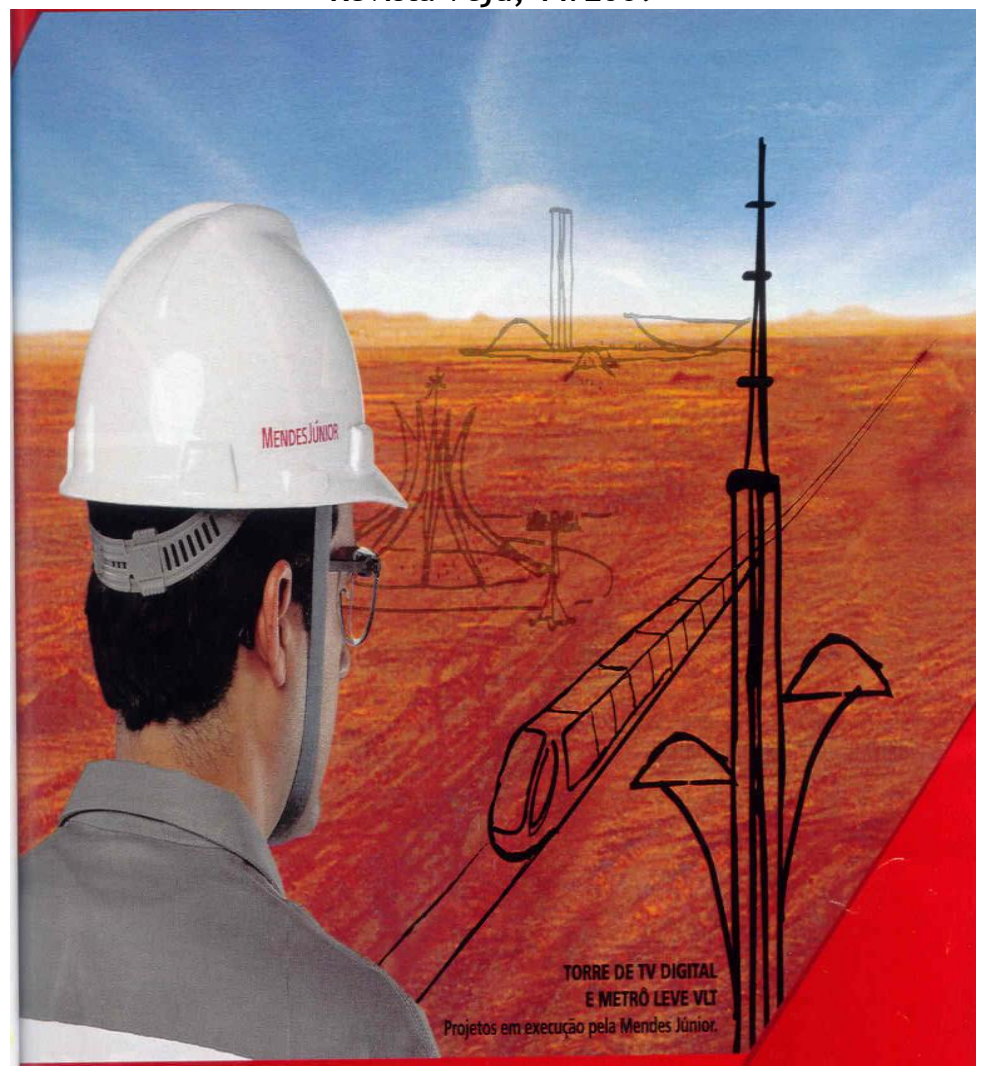

Fonte: Edição Especial, Abril, ano 42, n. 2.138, p. 47.

O texto acima é uma representação narrativa promocional que recontextualiza o evento de domínio público (os 50 anos da Capital Federal) representado na capa da revista Veja, com o propósito de transformá-lo em um evento de domínio privado. A recontextualização do evento cultural em gênero de governança, processo identificado pelo azul celeste no fundo do design e pelo cenário vermelho modulado no plano intermediário da imagem, sobre o qual a Praça dos Três Poderes ${ }^{8}$ aparece modalizada com elementos de outra prática (o metrô e a torre digital). O Congresso Nacional denota

\footnotetext{
${ }^{8}$ A Praça dos Três Poderes é o lugar onde o Palácio do Planalto (sede do Poder Executivo), o Congresso Nacional (sede do Poder Legislativo) e o Supremo Tribunal Federal (sede do Poder Judiciário) estão localizados.
} 
a natureza política da representação narrativa, mas funciona apenas como um participante secundário, ou seja, como uma circunstância locativa.

Nesta estrutura visual a narrativização é operacionalizada pela incorporação da perspectiva de ângulo perpendicular (de cima para baixo) que atribui potência máxima ao participante ator representado. Ainda que a distorção da perspectiva seja neutralizada, a transversalidade do vetor da estrutura indica a existência de ponto de vista persuasivo. A representação narrativa promocional é realizada pelo encaixamento do participante ator no primeiro plano da estrutura comunicativa-homem de uniforme cinza e de capacete de segurança com o nome da Empresa Mendes Júnior. Salientado por seu tamanho e pelo efeito do contraste da roupa cinza sobre o cenário vermelho no plano médio do design, o participante ator é ligado aos participantes alvo (o metrô e a torre de TV) pelo vetor da estrutura transacional (a linha do metrô).

Embora o participante principal seja representado como dado informativo relevante, sabemos que a valorização do trabalhador da construção civil não é comum em nossa sociedade capitalista. Além disso, a delocação do metrô e da torre de TV e a alocação de ambos na Praça dos Três Poderes, funcionando como participantes meta, denotam intenção real do texto: promover a Empresa Mendes Júnior, como mostra o fragmento extraído da Figura 6b:

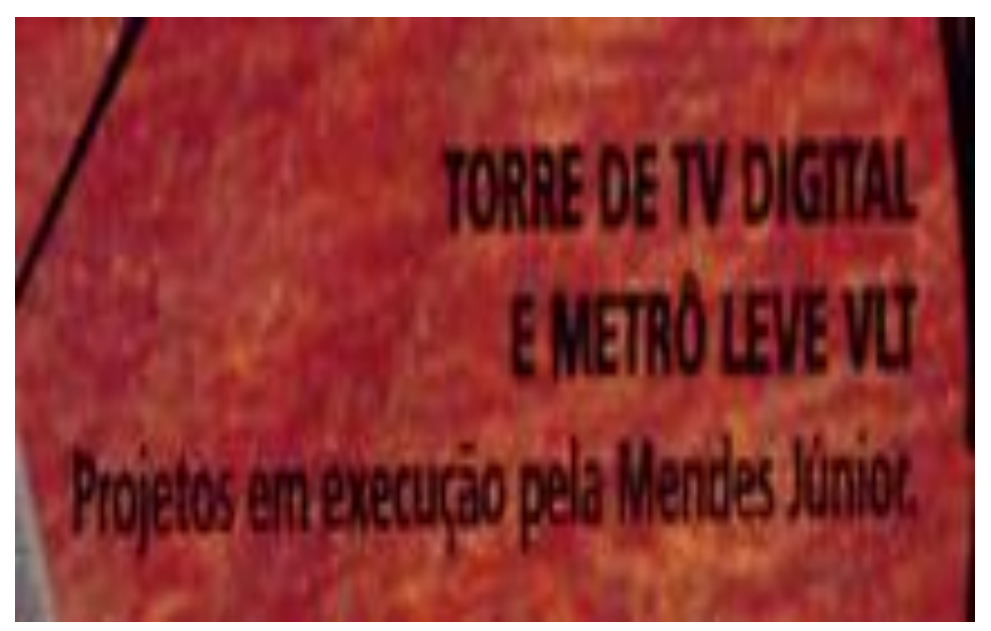

Outra análise da mesma representação narrativa (Figura 1b) identifica um processo mental formado da estrutura transacional já focalizada. Nesse caso, o vetor do processo de ação é o olhar do reator (supervisor de obra) sobre o fenômeno (o metrô). Com efeito, a Torre de TV, o Congresso Nacional e a Catedral de Brasília são 
representados como circunstâncias locativas que podem ser ignoradas, porque não afetam a proposição básica do padrão narrativo.

Em vista do exposto, concluímos que a análise das representação narrativa do evento cultural recontextualizado, seja esta interpretada com uma estrutura de ação transacional, seja interpretada como uma estrutura de ação reacional, expressa um único significado: o poder econômico é maior que o poder político, tanto que este age a serviço daquele.

\section{Considerações finais}

Esse estudo teve como objetivo analisar os modos semióticos de construção de significados de narrativas multimodais, difundidas por edição especial da revista Veja, as quais têm como contexto de produção o Aniversário de Brasília. Orientado pela metodologia transdisciplinar da Análise de Discurso Crítica, o estudo explicitou os contextos que indiretamente influenciam a prática de produção, de difusão e de consumo dos bens informativos da mídia contemporânea, o qual nos permite dizer que o poder da comunicação é operado e exercitado por uma prática econômico-política da qual se desenvolvem narrativas multimodais, cujos recursos semióticos utilizados, entre os quais, metáforas visuais e frames ${ }^{9}$ evocam significados ideológicos capazes de influenciar as ações e as tomadas de decisões do público consumidor. A orientação triádica - discurso, cognição e sociedade - fornecida pela Análise de Discurso Crítica também possibilitou a selecão de categorias sistematizadas pela Teoria Semiótica Social da Multimodalidade, tais como: gênero global, representação narrativa e modalidade, para a análise dos significados ativados, representados e identificados nas narrativas veiculadas pela midia impressa.

Com efeito, a análise da narrativa midiática, publicada na capa da edição especial da revista Veja, revelou de que modo um evento sociocultural de domínio público é eficazmente representado e modalizado com o propósito de perpetuar o poder de governância. A análise da narrativa veiculada na página 47 mostrou como a recontextualização visual e a narrativização estrategicamente incorporadas à representação narrativa midiática servem ao poder e à dominação.

\footnotetext{
${ }^{9}$ Frames são estruturas narrativas que correspondem às estruturas neurais resultantes da atividade cerebral ao longo dos tempos.
} 
Concluímos que o emprego de recursos estratégicos do modo visual no gênero midiático, que a incorporação de argumentos nas representações com o propósito de legitimar o poder e que os sentidos ideológicos compostos nos textos, por marcadores de modalidade, abrem questionamentos de verdade. Todavia, o envolvimento que as formas estabelecem com o receptor, além da unicidade de sentidos mantidos pela quase interação mediada pela mídia asseguram o efeito social planejado. Formas como estas podem ser apropriadas com relativa facilidade e reproduzidas como modelos para o exercício estratégico do poder e da dominção, devido ao significado potencial que elas projetam sobre a cognição social. Apesar de tudo, acreditamos que novos contextos possam nortear a elaboração consciente de produções sociopolíticas, mediante as quais a identidade cultural brasileira possa ser fortalecida.

\section{Referências}

BAUMAN, Z. Globalização: as consequências humanas. Rio de Janeiro: Jorge Zahar, 1999. BAUER, M. W.; GASKELL, G. Pesquisa qualitativa com texto, imagem e som: um manual prático. Petrópolis, Rio de Janeiro: Vozes, 2005.

BOURDIEU, P. Outline of a Theory of Practice. Cambridge: Cambridge University Press, 1977.

CASTELLS, M. A. Communication power. New York: Oxford University Press, 2009.

DENZIN, N. K.; LINCOLN, Y. S. 2006. O planejamento da pesquisa qualitativa: teorias e abordagens. Porto Alegre: Artmed Editora, 2006.

FAIRCLOUGH, N. Media Discourse: voices. London: Edward Arnould, 1995.

Analysing discourse: textual analysis for social research. London: Routledge, 2003.

Language and globalization. London; New York: Longman, 2006.

Critical Discourse Analysis: the critical study of language. 2. ed. London: Longman, 2010.

HALLIDAY, M. A. K. An introduction to funcional grammar. London: Arnold, 1985.

JEWITT, C. The routledge handbook of multimodal analysis. London and New York: Routledge, 2011.

KRESS, G; VAN LEEUWEN, T. Reading images: the grammar of visual design. London: Routledge, 2006. 
KRESS, G. Multimodality: a social semiotic approach to contemporary communication. London and New York: Routledge, 2010.

MACHIN, D.; VAN LEEUWEN, T. Global media discourse: a critical introduction. London and Ney York: Routledge, 2001.

MCQUAIL, D. Teorias da Comunicação de Massa. Trad. Roberto C. Costa. Porto Alegre: Penso, 2013.

MOTTA, L. G. Análise Crítica da Narrativa. Brasília: Universidade de Brasília, 2013.

SILVERSTONE, R. Porque estudar a mídia? São Paulo: Edições Loyola, 3a ed. 2011.

THOMPSON, J. B. Ideologia e cultura moderna: teoria social crítica na era dos meios de comunicação de massa. Petrópolis: Vozes, 2011.

A mídia e a modernidade: uma teoria social da mídia. Petrópolis: Vozes, 2012.

Discurso e Contexto: uma abordagem sociocognitiva. Trad. Rodolfo Ilari. São Paulo: Contexto, 2012.

VAN DIJK, T. New Analysis: case studies of international and national news in the press. New York and London: Routledge, 2011.

VAN LEEUWEN, T. Introducing social semiotics. London, Routledge, 2005.

- Discourse and Practice: new tools for critical discourse analysis. Oxford:

University Press, 2008.

VEJA. 2009. 50 anos de Brasília. São Paulo: Abril, novembro, Edição Especial, ano 42, n. 2.138 .

\section{Sites}

Html.www. google. com

Disponível em http://terradeencantosbrasil. Acesso em 14/10/2014.

Html.www.google.com.

Disponível em http://veja.abril.com.br/especiais/brasilia/primeira-vez-mapa-p020.htmlwww.google. com. Acesso em 14/10/2014. 

v. 3 (1), p. 63-90. 2018 